Molecular Models for the Intercalation of Hydrogen Molecules into Modified Graphites

Daniel F. Calef

RECEIVED

APR 05 ISU6

OSTI

December 1995

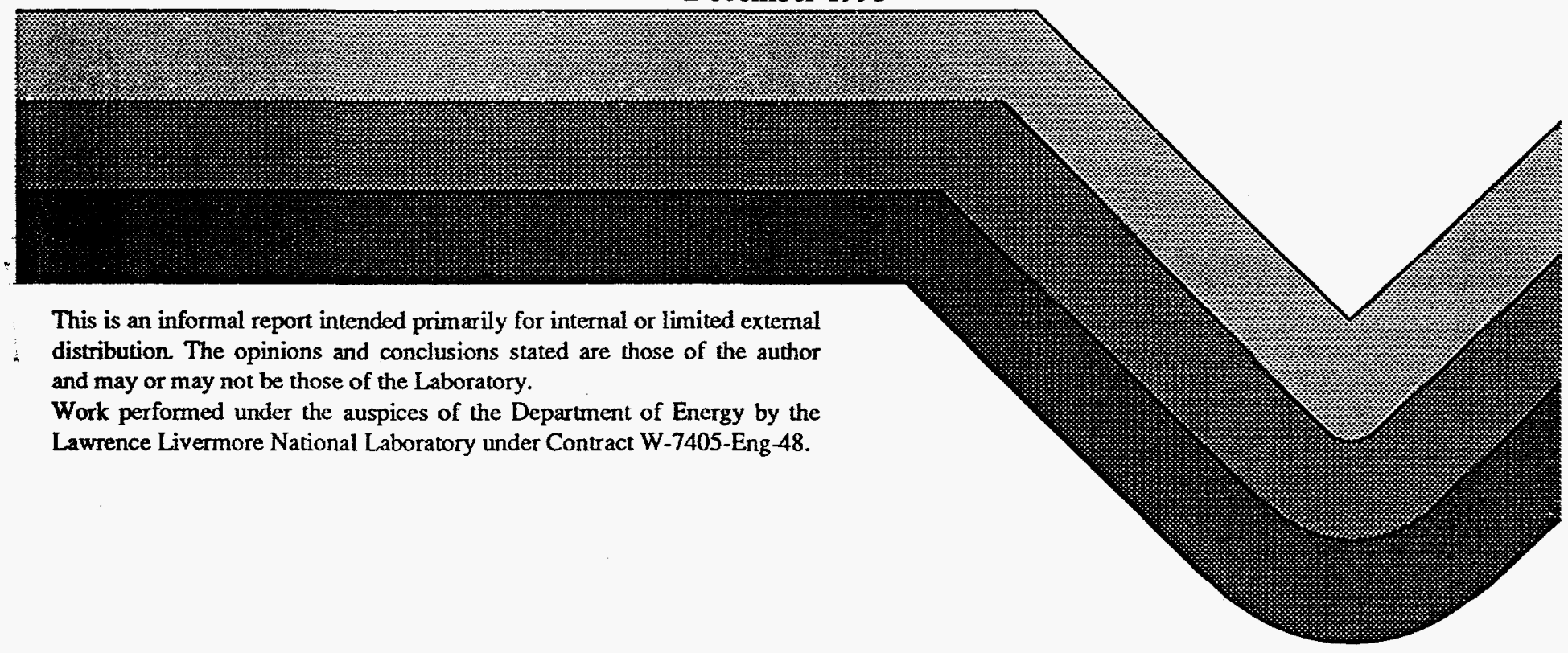




\section{DISCLAIMER}

This document was prepared as an account of work sponsored by an agency of the United States Government. Neither the United States Government nor the University of California nor any of their employees, makes any warranty, express or implied, or assumes any legal liability or responsibility for the accuracy, completeness, or usefulness of any information, apparatus, product, or process disclosed, or represents that its use would not infringe privately owned rights. Reference herein to any specific commercial products, process, or service by trade name, trademark, manufacturer, or otherwise, does not necessarily constitute or imply its endorsement, recommendation, or favoring by the United States Government or the University of California. The views and opinions of authors expressed herein do not necessarily state or reflect those of the United States Government or the University of California, and shall not be used for advertising or product endorsement purposes.

This report has been reproduced directly from the best available copy.

A vailable to DOE and DOE contractors from the Office of Scientific and Technical Information P.O. Box 62, Oak Ridge, TN 37831

Prices available from (615) 576-8401, FTS 626-8401

A vailable to the public from the National Technical Information Service

U.S. Department of Commerce 5285 Port Royal Rd. Springfield, VA 2216 


\section{DISCLAIMIER}

Portions of this document may be illegible in electronic image products. Images are produced from the best available original document. 


\title{
Molecular Models for the Intercalation of Hydrogen Molecules into Modified Graphites
}

\author{
Daniel F. Calef \\ Chemistry and Materials Science Directorate \\ Lawrence Livermore National Laboratory \\ University of California \\ P.O. Box 808, Livermore CA 94551
}

\begin{abstract}
Quantum chemical calculations were performed on a series of substituted polyaromatic ring compounds. Parallel "sandwiches" of these compounds were used as a model of graphite. Hydrogen was introduced between the compounds as a model of $\mathrm{H}_{2}$ intercalated into graphite. It was found that it required work to insert the $\mathrm{H}_{2}$ into most of the compounds, except when the presence of the hydrogen allowed the compound to find a new configuration with a lower energy.
\end{abstract}

\section{Introduction}

Carbonized aerogels have been proposed as a medium for the storage of $\mathrm{H}_{2}$ gas.

Aerogels, in general, can have a variety of complex structures. They are complicated three dimensional disordered networks built from intermediate size molecular clusters. The structure of the network is a fascinating problem, but for hydrogen storage is of less relevance, as the hydrogen molecule is so small that variance of pore sizes on the order of hundreds to thousands of Angstrom scale would seem unlikely to vary the trapping ability of the aerogel.

What would seem most important at the Angstrom length scale is the interaction of the hydrogen molecule with the individual carbon clusters. Commonly referred to as "beads," the clusters have sizes that range from ten to a few hundred Angstroms. The carbon in these clusters appears to be graphitic with an ample degree of disorder. The question for hydrogen storage then is, how does a hydrogen molecule interact with these graphitic clusters, or what can be done to these clusters to encourage hydrogen storage?

The storage mechanism explored was intercalation of hydrogen molecules between the graphitic sheets. It is extremely difficult to see absorption of hydrogen molecules on graphite surfaces except at extreme cryogenic conditions (M. Balooch, personal communication). 


\section{Model and Methods}

Two parallel coronene molecules (Figure 2) were used as a model of graphite. These are polyaromatic rings with twenty four carbons each. This molecule was chosen as the largest molecular cluster model that could be handled with existing computer power. A hydrogen molecule placed at the center between the two molecules would be 3.5 Angstroms from the edge or "surface" atoms. Since the hydrogen bond length is on the order of 0.75 Angstroms, the local environment of the hydrogen should resemble graphite and minimize any direct interaction between the hydrogen molecule and the surface atoms.

In order to create different environments, the hydrogens were replaced by the series $\mathrm{F}, \mathrm{Cl}$, $\mathrm{Br}, \mathrm{I}, \mathrm{OH}, \mathrm{NH}_{2}, \mathrm{CH}_{3}, \mathrm{SH}, \mathrm{PH}_{2}$. This provides a data set of ten data compunds. Initially, it was anticipated that this would simply vary the initial equilibrium separation between the two coronene molecules. However, as will be discussed, these substitutions caused a host of effects.

On each of these compounds, the geometry of the complex was varied to find the configuration with the lowest energy. A hydrogen molecule was placed in the center directly between the two substituted coronenes and the geometry optimized again. In the simplest cases, these calculations can be thought of as giving us three pieces of information - the initial preferred interplanar distance, the preferred interplanar distance with the $\mathrm{H}_{2}$ in between and the energy change.

The calculations were performed using the ${ }^{1}$ MOPAC semi-empirical quantum chemical package. Semi-empirical calculations replaced terms in the Hartree Fock equations for true ab-initio calculations with simple empirical functions. True ab-inito calculations are not feasible for this system as the calculations discussed here have roughly five times the number of heavy atoms than can be treated with ab-initio methods. The empirical terms were adjusted both to duplicate the ab-initio results on small compounds and to match available experimental information. For example, the experimentally known geometries and heats of formation were used. One important result of including experimental information is that, in some sense, the semi-empirical calculations can be thought of as "containing" effects that are only present in very high order ab-initio calculations. There are several available parameterizations - the $\mathrm{MNDO} / 3$ parameters were used as they seemed to do the best for an isolated hydrogen molecule.

In addition to the semi-empirical calculations, a number of true ab-initio calculations using ${ }^{2}$ Gaussian92 were performed on the system of $\mathrm{H}_{2}$ and benzene. These calculations were performed initially to test the semi-empirical results. 


\section{Results}

The results of these calculations yield information on several aspects of the nature of hydrogen intercalation.

One question that is answered immediately is whether the hydrogen molecule would dissociate into atomic hydrogen in the graphitic environment. Based on these calculations, it can be concluded that the hydrogen molecule does not dissociate in the graphitic environment. In all of the calculations the initial configuration started with the two hydrogen atoms at their equilibrium bond distance. After energy minimization no hydrogen molecules were dissociated. It is possible that there was a barrier that the calculations could not cross, but at low temperatures neither could the real system. In some circumstances very large distortions of the coronenes occurred, so the software program was capable of finding minima greatly perturbed from the starting geometry.

A higher quality ab-initio study of the benzene hydrogen system showed no tendency of the two molecules to form a complex or for the $\mathrm{H}_{2}$ to dissociate. The calculations were performed with a very high quality basis set (technically G6-31**) at the Hartree Fock level. This is the highest quality basis set used for traditional organic molecules. The calculations are in agreement, in a general sense, with the experimental results of $\mathrm{H}_{2}$ on graphite, "It's like a little $\mathrm{BB}$," (M. Balooch, personal communication). If there is any significant interaction it would require very time-consuming post-Hartree Fock calculations.

The main results are summarized in Figure 1. This plot shows both the geometry and energy change between the two parallel substituted coronene molecules before and after a hydrogen molecule is placed in the middle. The energy change, in kcals, is shown on the vertical axis and the geometry change, in Angstroms, is shown on the horizontal axis. The initial configuration is the left end of the line and the final point the right end. For clarity, each point is displaced vertically by $5 \mathrm{kcals}$ from the previous point.

Although the data seems at first glance quite complicated, it can be understood by dividing the results into two groups.

The first group consisted of the unsubstituted coronenes and the $\mathrm{F}, \mathrm{Br}, \mathrm{OH}, \mathrm{SH}$, and $\mathrm{PH}_{2}$ substituted coronenes. In these systems the coronenes essentially remained planar and the effect of substitution was mainly to change the preferred initial separation. Introduction of an $\mathrm{H}_{2}$ molecule always led to an increase in the separation and some increase in the total energy of the complex. This is shown in Figures 3 and 4 for the unsubstituted coronenes. The trend in this set was that the larger the initial separation, the larger the change in the distance but at a smaller energy cost. 
The second group, $\mathrm{Cl}, \mathrm{I}, \mathrm{CH}_{3}$, and $\mathrm{NH}_{2}$ substituents, can cause considerable distortion in the coronene ring system. These systems, with and without the $\mathrm{H}_{2}$, are shown in Figures 4 through 11. The major cause of distortion was steric interaction between bulky substituents, although in the case of the halogens the interplay between electronic interactions (weakening ring bond strength) and steric interactions, seemed to be the reason why some $\mathrm{Cl}$ and I caused major distortions and $\mathrm{Br}$ did not. The large degree of distortion in these compounds implies that there are a great number of configurations that are "local minima" of energy in configuration space. The introduction of a hydrogen molecule caused the system to relax to a new local minima, usually lower in energy and with the molecules further apart. The iodine compound is a very good example, where the initial configuration was roughly planar, but introducing the $\mathrm{H}_{2}$ forced the rings apart and much greater distortion (and a lower energy) was possible. $\mathrm{The}_{3} \mathrm{CH}_{3}$ compound seemed to move apart in the manner of the first group, but with a much higher energy cost.

The $\mathrm{NH}_{2}$ compound (Figures 10 and 11 ) in that the hydrogen molecule seemed to migrate to the surface of the cluster and it also showed the largest decrease in energy. This was the only evidence in this set of compounds of possible direct chemical interaction between $\mathrm{H}_{2}$ and a substituent.

In order to make any of the calculations on the highly distorted compounds truly quantitative, it will be necessary to perform a large series of calculations to sample the extremely large number of local energy minima available to these clusters.

Calculations were also run on coronene molecules with two and three $\mathrm{H}_{2}$ sandwiched between them. It was expected that there would be little energy cost for the introduction of additional hydrogens. However, when the calculations were run ailowing the hydrogen molecules to vary position, invariably one or more of the hydrogen molecules was simply ejected from the sandwich.

As stated previously, these calculations involved essentially some of the largest possible systems that can be treated quantum mechanically with available computer technology, in that both new hardware and substantial software modification would be required to treat larger systems.

Future efforts will focus on the calculation using classical molecular dynamics for the mobility of hydrogen molecules in much larger model graphite structures. This mobility can be related to the diffusion coefficient, which in turn can be related to loading response to the graphite to varying concentrations of $\mathrm{H}_{2}$ gas. 


\section{Conclusions}

1. There is no calculational evidence that the $\mathrm{H}_{2}$ molecules dissociate in the model graphite environment.

2. Interaction between the $\mathrm{H}_{2}$ and relatively undistorted carbon rings is "repulsive," in that it generally requires energy to place the $\mathrm{H}_{2}$ between the rings. The resulting clusters have the $\mathrm{H}_{2}$ in a local energy minima.

3. Increasing the spacing between carbon layers decreases the energy required to insert the hydrogen.

4. Only the $\mathrm{NH}_{2}$ compound shows any evidence that there is direct chemical interaction between the substituents and the $\mathrm{H}_{2}$. In all other cases, all effects of substituents are in changing the carbon system.

5. Highly distorted systems can "bind" hydrogen by being forced by the presence of the intercalated molecule into a different local energy minima. Quantitative studies of these systems would require a method to average over a large number of configurations.

\section{References}

1J. J. P. Stewart, QCPE 18, 455 (1986).

${ }^{2}$ Gaussian92, Revision B, M. J. Frisch, G. W Trucks, M. Head-Gordon, P. M. W. Gill, M. W. Wong, J. B. Foresman, B. G. Johnson, H. B Schlegel, M. A. Robb, E. S. Replogle, R. Gomperts, J. L. Andres, K. Raghavachari, J. S. Binkley, C. Gonzalez, R. L. Maartin, D. J. Fox, D. J. Fox, D. J. Defrees, J. Baker, J. J. P. Stewart, J. A. Pople, Gaussian Inc., Pittsburgh, PA, 1992.

\section{Figure Captions}

1. Change of energy and geometry with the introduction of a hydrogen molecule into the substituted coronene cluster. Vertical axis is energy in kcals. Horizontal axis is the average interplanar distance in Angstroms. Each compound is vertically displaced by $5 \mathrm{kcals}$ from the previous compound. The left end of the line is that the equilibrium distance of the cluster without the hydrogen. The right end of the line is at the equilibrium distance with $\mathrm{H}_{2}$ intercalated, displaced vertically by the energy change.

2. Original coronene sandwich.

3. Coronene with $\mathrm{H}_{2}$.

4. Chlorinated compound.

5. Chlorinated compound with $\mathrm{H}_{2}$.

6. Iodinated compound.

7. Iodinated compound with $\mathrm{H}_{2}$. Note the increased distortion. 
8. Methylated compound.

9. Methylated compound with $\mathrm{H}_{2}$.

10. Ammoniated compound.

11. Ammoniated compound with $\mathrm{H}_{2}$. Note how the $\mathrm{H}_{2}$ has migrated to the surface region near the $\mathrm{NH}_{2}$ groups. 


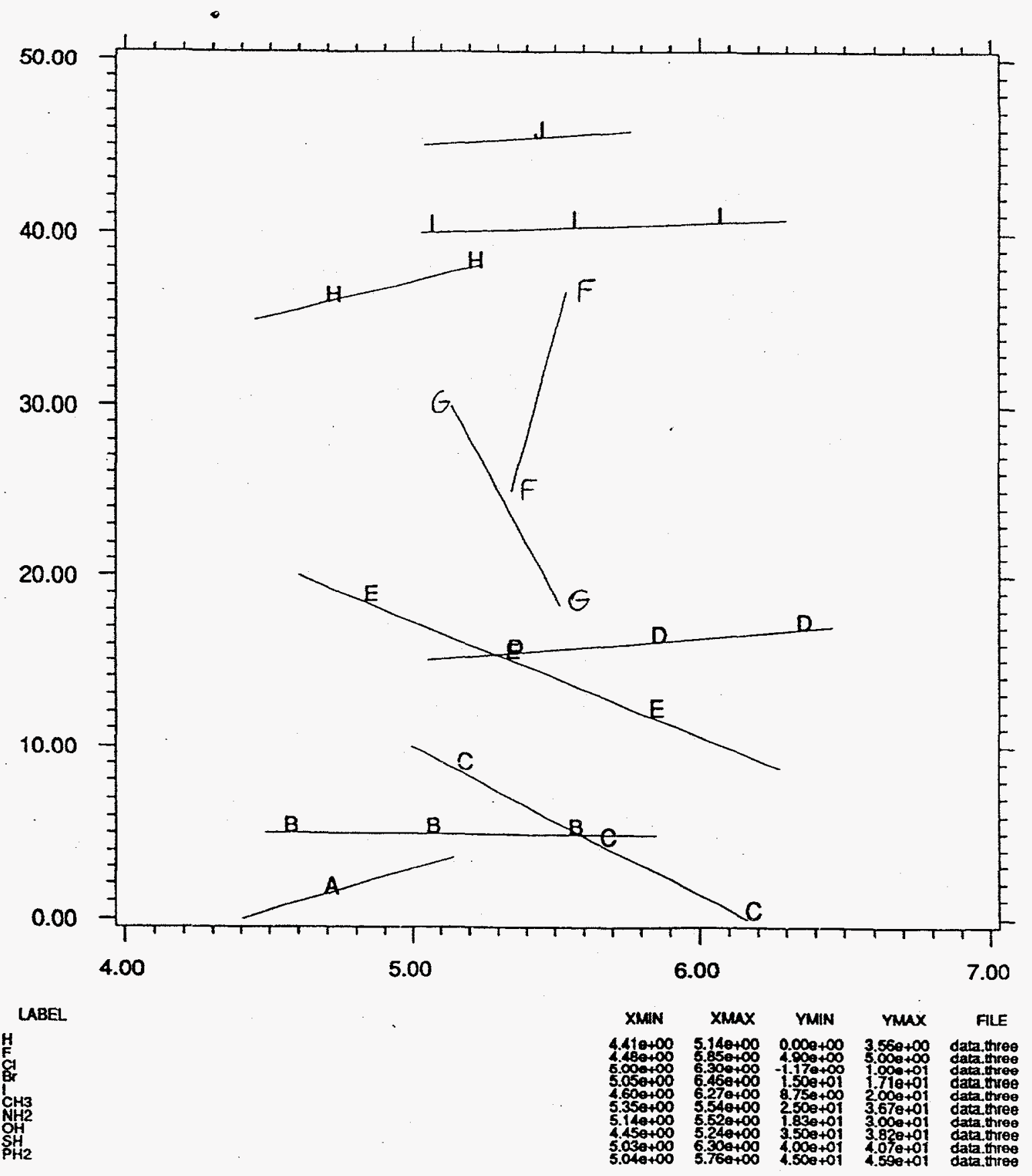

Figure 1. Change of energy and geometry with the introduction of a hydrogen molecule into the substituted coronene cluster. Vertical axis is energy in kcals. Horizontal axis is the average interplanar distance in Angstroms. Each compound is vertically displaced by $5 \mathrm{kcals}$ from the previous compound. The left end of the line is that the equilibrium distance of the cluster without the hydrogen. The right end of the line is at the equilibrium distance with $\mathrm{H}_{2}$ intercalated, displaced vertically by the energy change. 

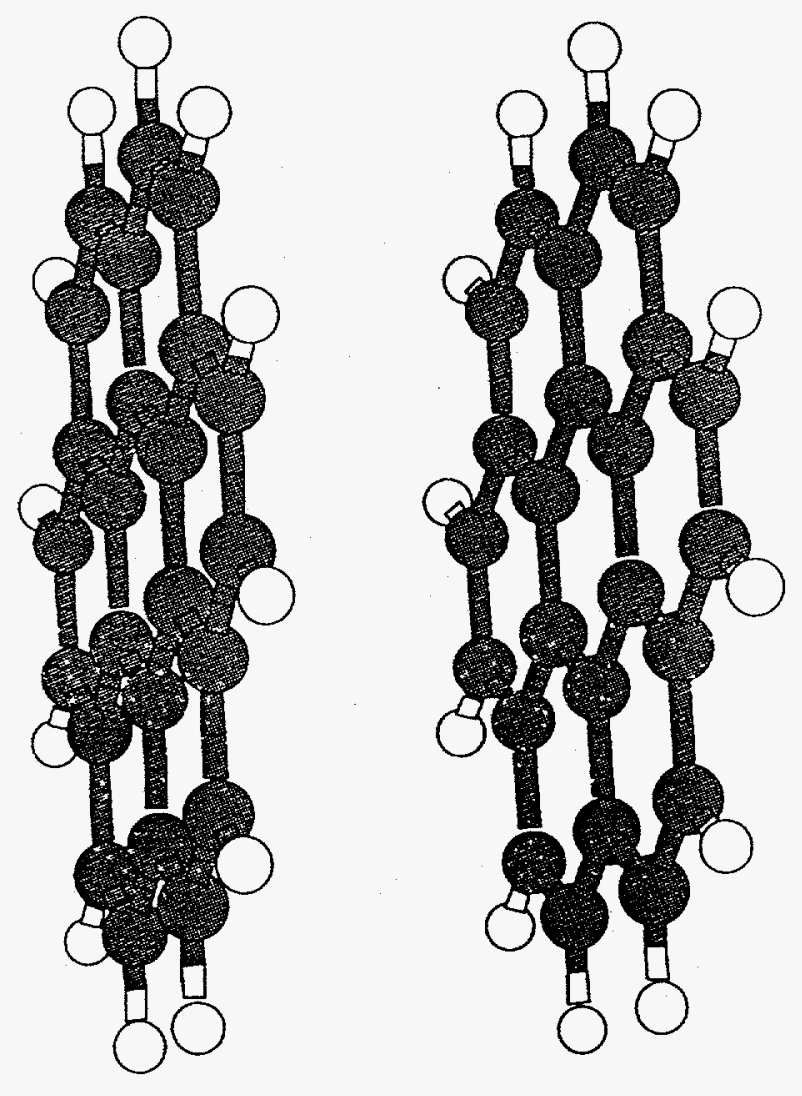
Active

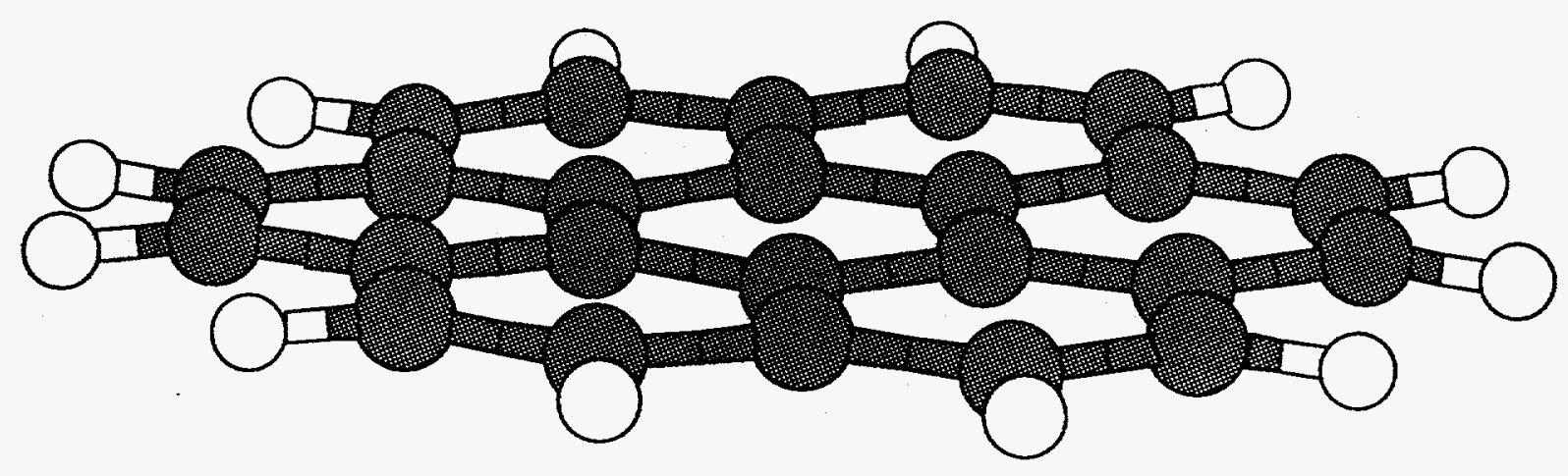

00

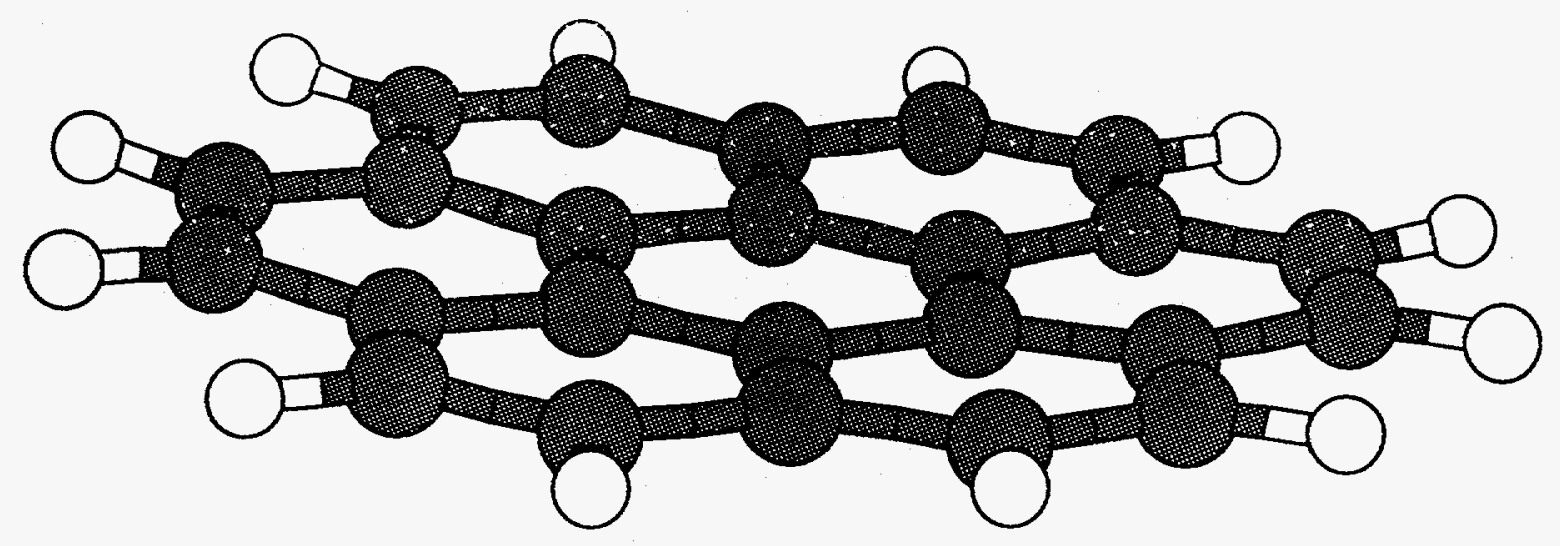


Active<smiles>[X][Z][3H]</smiles>
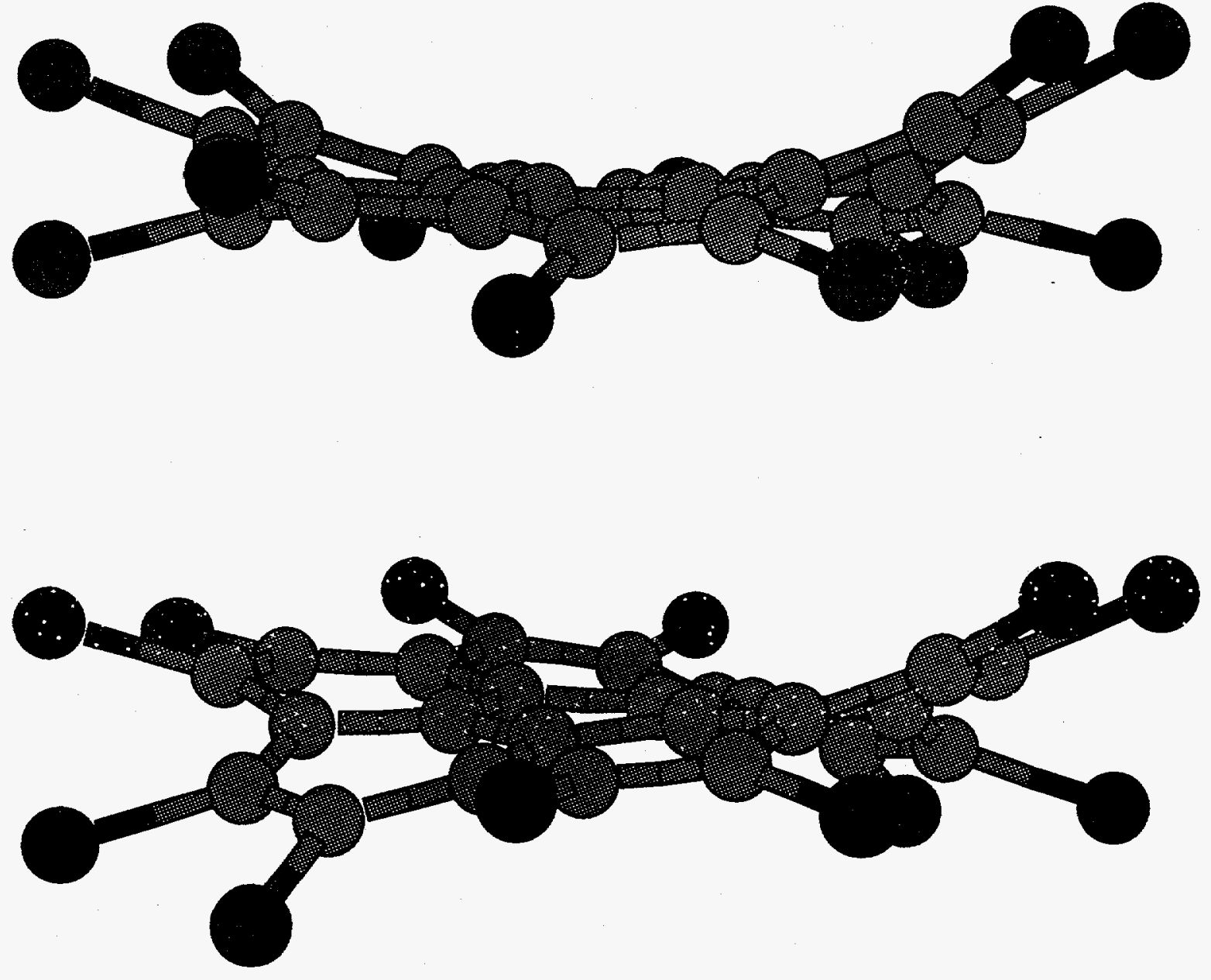<smiles>CCC(C)C(C)C</smiles> 



$$
=
$$




$$
=
$$



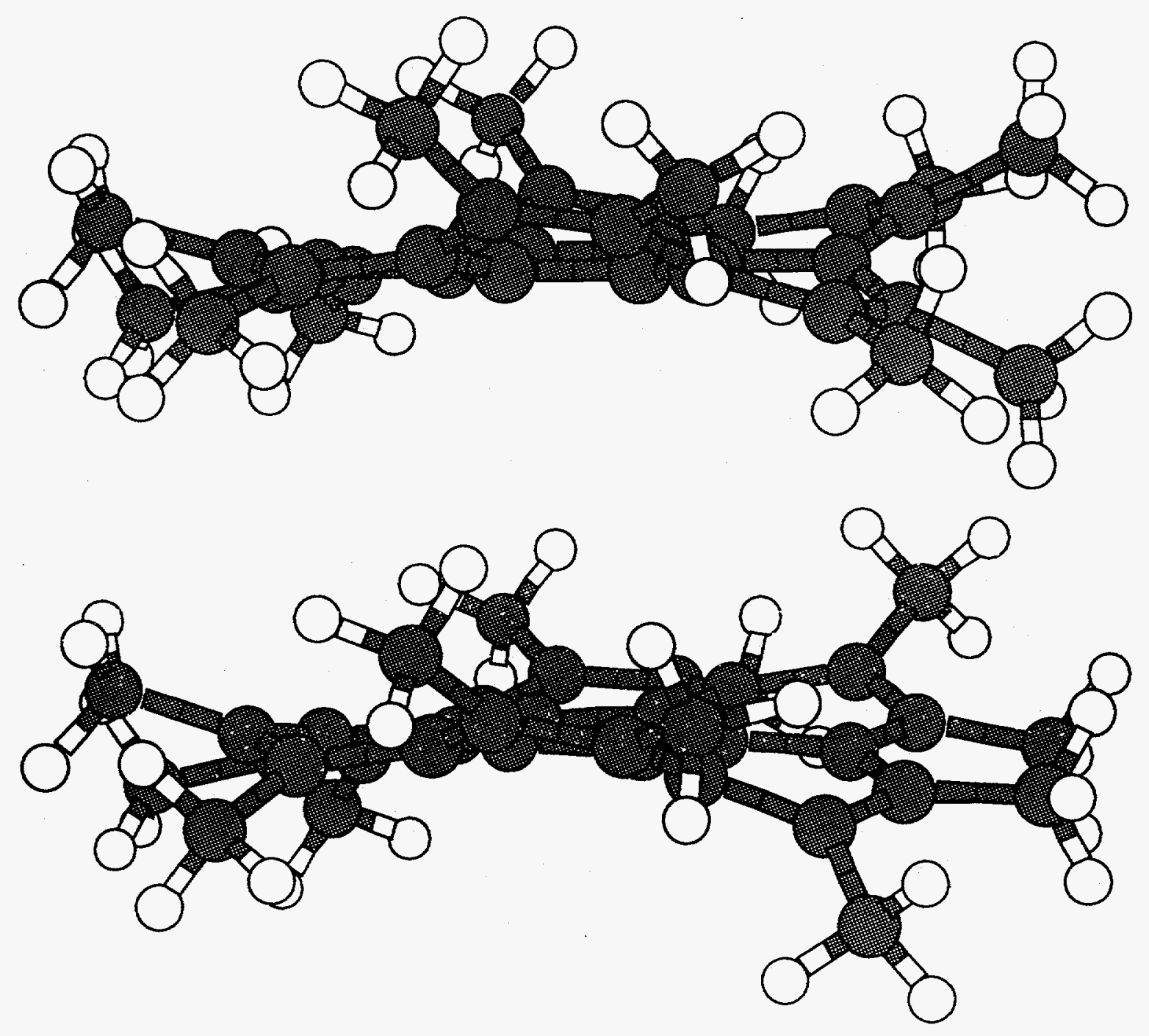

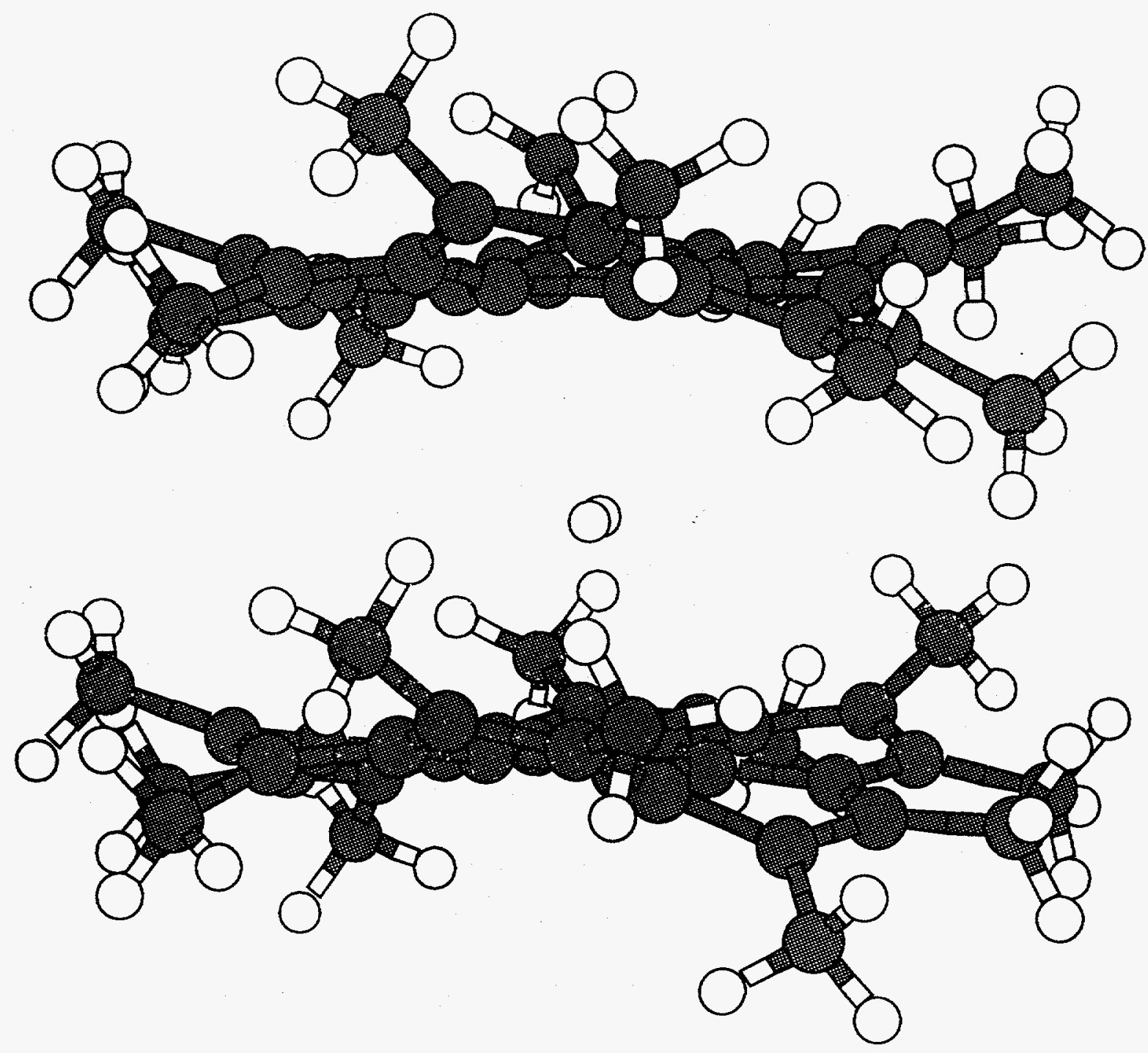

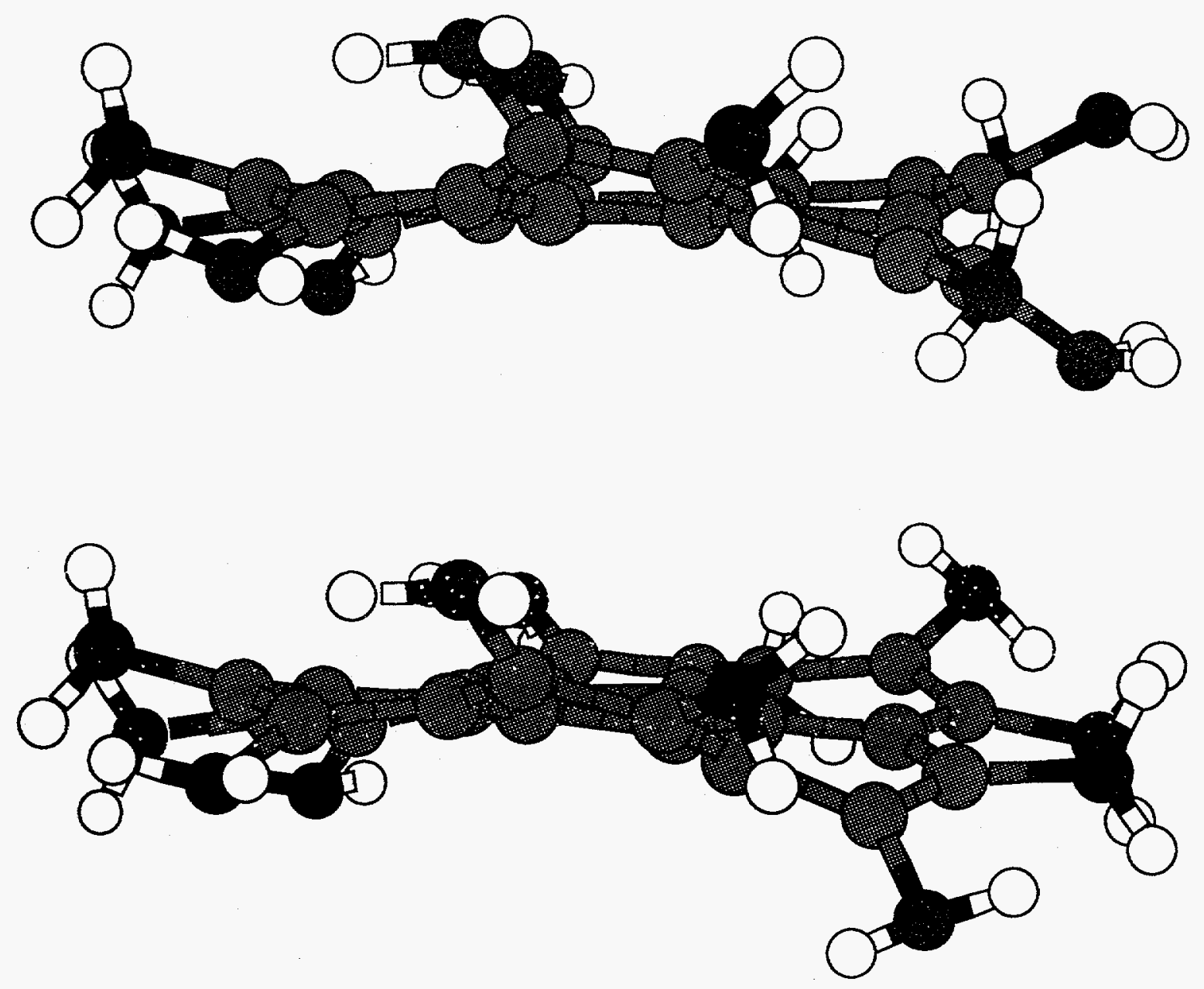

$$
\begin{aligned}
& \text { pur "N"No" } \\
& \text { ont blat antede }
\end{aligned}
$$



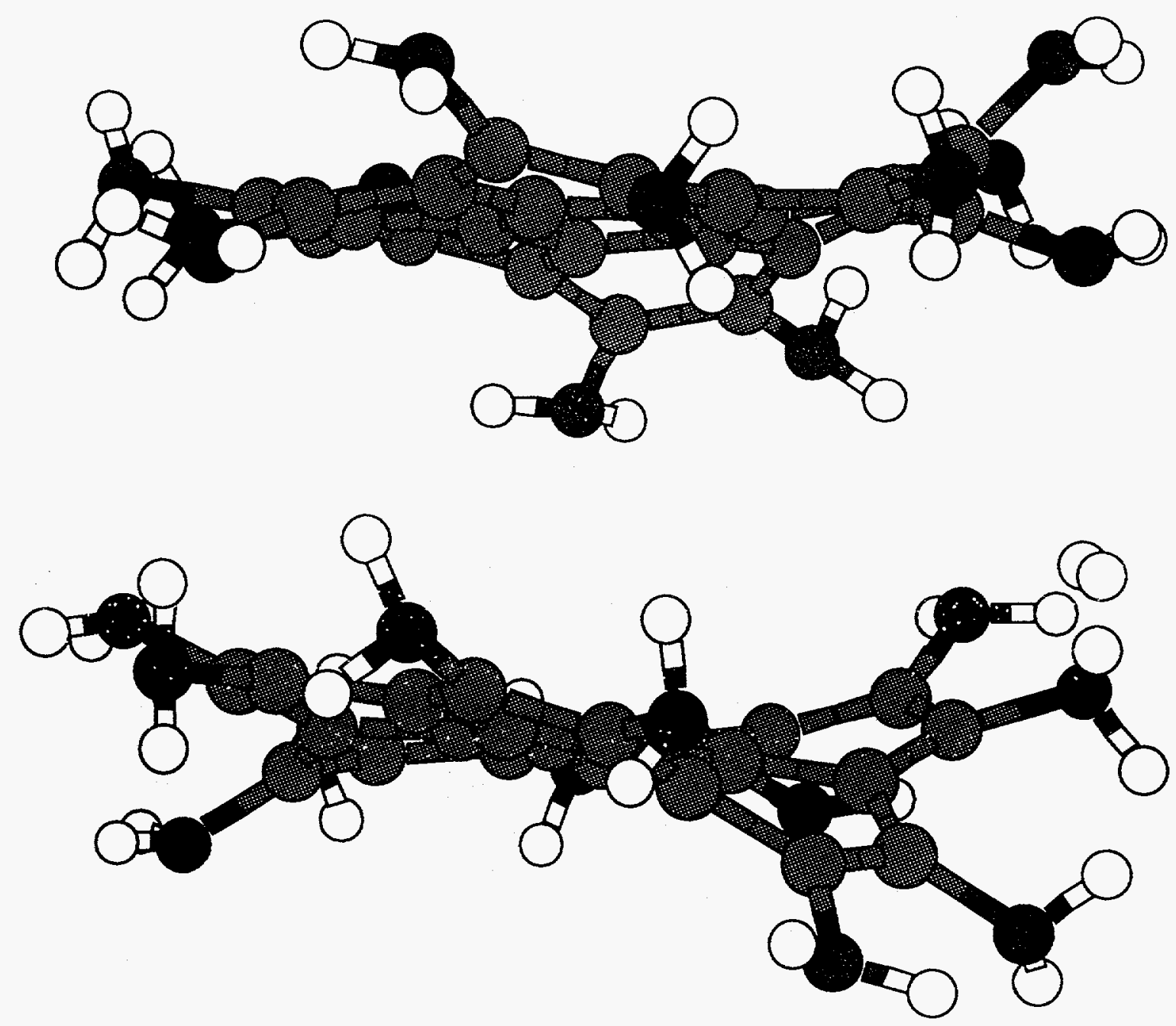